Revista de Ciencias Sociales - Número 70 (2017) - Páginas 95-121

La técnicas de anticipación de la respuesta penal...

\title{
LAS TÉCNICAS DE ANTICIPACIÓN DE LA RESPUESTA PENAL VS LOS PRINCIPIOS DEL DERECHO PENAL
}

\author{
THE TECHNIQUES OF ANTICIPATION OF THE \\ ANSWER PENAL VS PRINCIPLES \\ OF THE PENAL RIGHT
}

\author{
MANUEL ALBERTO LEYVA ESTUPIÑÁN* \\ Universidad de Holguín, Cuba \\ mleyvae@fh.uho.edu.cu \\ ROSABEL FRANCISCA MEDINA SARMIENTO** \\ Universidad de Holguín, Cuba \\ LARISBEL LUGO ARTEAGA*** \\ Universidad de Holguín, Cuba \\ llugo@fh.uho.edu.cu
}

\section{Resumen}

Los autores sostienen que el fenómeno de la anticipación de la tutela penal se manifiesta en el ámbito legislativo con la aparición de las técnicas

* Profesor Auxiliar de la Universidad de Holguín. Profesor Principal de Derecho Penal. Jefe del Departamento de Derecho de la Facultad de Ciencias Sociales y Jurídicas. Miembro de la Sociedad Cubana de Ciencias Penales. Especialista en Derecho Penal por la Universidad de Holguín. Artículo recibido el 27 de septiembre de 2016 y aceptado el 13 de marzo de 2017.

* Licenciada en Derecho por la Universidad de Holguín. Adiestrada en la Dirección Provincial de Justicia en la provincia de Holguín, Cuba.

** Profesora Asistente de la Universidad de Holguín. Profesora Principal de Derecho Penal Especial del Departamento de Derecho de la Facultad de

Revista de Ciencias Sociales - Número 70 (2017) - Universidad de Valparáíso - ISSN 0716-7725-Valparaíso, Chile 
anticipación de la tutela penal, que intervienen cada vez con más frecuencia en el ámbito previo, su origen se encuentra ligado al Derecho Penal de Riesgo, tendencia expansionista del Derecho Penal que es contraria a principios jurídico-penales esenciales. En consecuencia, realizamos un análisis de las figuras delictivas que representan una antelación de la intervención penal partiendo del estudio de las diferentes técnicas. A partir del cual se derivan importantes reflexiones acerca de la necesidad de incluirlas en las legislaciones penales actuales, haciendo de ellas la excepción y no la regla.

\section{Palabras clave}

Anticipación tutela penal, principio de intervención mínima, técnicas de anticipación de la tutela penal.

\section{Abstract}

The authors maintains that the phenomenon of the anticipation of the penal tutelage is shown at the legislative space with the appearing of anticipation of the penal tutelage techniques, that they intervene each time with more frequency on the previous space, its origin finds in Risk's Penal Law, tendency penal expansionist of The Penal Law that goes against essential juridical penal principles. In consequence, the author in her research makes an analysis of the conducts that represent an anticipation of the penal tutelage; departing from the particular study of the different techniques, they derive important reflections about the need to include them in the penal presentday legislations, making of them the odd man out and it does not rule it.

\section{Keywords}

Anticipation penal tutelage, minimal intervention principles, anticipation of the penal tutelage techniques.

\section{Introducción}

Las actuales sociedades modernas industrializadas están llenas de excesivos riesgos que nos atemorizan a diario por lo que en nuestra realidad actual resulta inquietante la preocupación sobre el papel que

ciencias sociales y Jurídicas. Miembro de la Sociedad Cubana de Ciencias Penales. Especialista en Derecho Penal por la Universidad de Holguín.

Facultad de Derecho y Ciencias Sociales - Universidad de Valparaíso - Chile 
le corresponde desempeñar al Derecho Penal frente a la aparición de nuevas formas de criminalidad, apreciándose esta tendencia a tipificarlas como resultado de la expansión del Derecho Penal contemporáneo.

En el ámbito de esta nueva sociedad, denominada "sociedad de riesgo", ha surgido entonces un "Derecho Penal de la sociedad de riesgo" o "Derecho Penal de riesgo", que ha experimentado una expansión apreciable en la magnitud de los marcos sancionadores de los delitos ya existentes como en el surgimiento de nuevos tipos delictivos. Entre sus características esenciales se encuentra el progresivo aumento en la anticipación de la tutela penal, que es una ampliación hacia esferas sociales que antes no constituían objeto de su intervención, valiéndose para ello de diferentes técnicas, fundamentalmente las más utilizadas son los delitos de peligro, de tentativa y de emprendimiento, la punición como delitos independientes de actos preparatorios, los delitos de intención sin lesión a un bien jurídico y la creación de bienes jurídicos colectivos. Mientras se realiza la intervención punitiva adelantada, indudablemente se atenta contra los principios esenciales del Derecho Penal como puede ser el carácter fragmentario del Derecho Penal o el de subsidiaridad, que han construido la base desde esta rama del Derecho desde sus inicios.

La anticipación de la tutela penal, que es la característica esencial del expansionismo conocido mundialmente como "Derecho Penal de riesgo" se ha convertido en una práctica cotidiana de la que dan fe los Códigos Penales actuales. La adelantada intervención se refleja en la ampliación de los límites punibles, podríamos decir que tiene un carácter preventivo, que parece constituir su principal finalidad, pudiendo interpretarse que se realiza de acuerdo a la máxima jurídico-penal "es mejor precaver que tener que castigar", cuando lo que resulta verdaderamente lamentable es ver cómo se reducen las garantías individuales. La prevención general mediante la pena alerta a los ciudadanos para que se abstengan de realizar conductas delictivas, pretendiéndose acaso que el Derecho ejercite su función educativa, se valen para ello de la coacción psicológica.

Consideramos oportuno tratar en este trabajo investigativo las cuestiones mencionadas que ciertamente nos hacen reflexionar sobre la necesidad de recurrir al Derecho Penal como vía de solución ante los

Revista de Ciencias Sociales - Número 70 (2017) - Universidad de Valparáíso - ISSN 0716-7725-Valparáiso, Chile 
nuevos conflictos en tiempos en los que se avecinan nuevas trasformaciones legislativas de las que no se encuentra exenta la normativa penal, es importante orientar el rumbo de nuestro Derecho Penal, lejos del expansionismo desmedido de las tendencias modernas que replantean los principios de este.

\subsection{Principios del Derecho vs Expansión}

Mayoritariamente se asocia la mención del Derecho Penal con la sanción y es que desde sus comienzos esta rama del Derecho ha tenido la tarea de castigar de la manera más dura las violaciones de la ley penal, que es expresión del poder coercitivo del Estado mediante el ius puniendi, imponiendo como consecuencia jurídica penal la sanción al individuo. La evolución del hombre se ha reflejado en sus leyes penales en las que progresivamente se introdujeron garantías en beneficio de quienes las infringían a la par que para su implementación se consideraban principios esenciales, límites de la potestad sancionadora del Estado, orientadores del Derecho Penal que permiten que discurra por los cauces de la justicia y atente en la menor medida contra las garantías individuales de los ciudadanos en un Estado Garantista.

Los principios han sido tema de arduas discusiones científicas, es inexistente hasta el momento una concepción unitaria al respecto. Se consideran normas incluidas en el derecho positivo que precisan reconocimiento constitucional a contrario censo son admitidos como juicios de valor anteriores a la creación de la norma positiva. En el Derecho Penal se entienden como límites a la potestad sancionadora del Estado, constituyen la esencia del sistema penal por lo que usuarios o investigadores los asumen por ser indispensables para trabajar, comprender o usar dicho sistema.

\section{Intervención mínima}

El principio de intervención mínima nace con el Liberalismo, la máxima expresión de los ideales de esta doctrina en el Derecho Penal se manifiestan en la obra de Cesare Beccaria "De los delitos y de las penas" (1764), en el que expone los fundamentos de un sistema penal

Facultad de Derecho y Ciencias Sociales - Universidad de Valparaíso - Chile 
garantista, limitador del poder punitivo en el que se basan muchas de las posiciones doctrinales sostenidas en la actualidad. El sistema presentado por Beccaria estaba conformado por un grupo de garantías que limitaban la intervención punitiva del Estado, del cual formaba parte el principio de intervención mínima, su obra defendía la reducción de las leyes penales, basándose en que si lo más importante era la prevención de los delitos, aumentar el rol de delitos era, también, elevar la probabilidad de que se cometiesen, lo constituye la primera expresión de aludido principio.

Hasta la actualidad ha trascendido este importante principio como una garantía frente al poder punitivo del Estado, siendo el pilar en que generalmente se sustentan los ordenamientos jurídico-penales de los estados, lo cual implica que la intervención del Derecho Penal se realice solo en caso de ataques muy graves a bienes jurídicos de gran importancia, en virtud de los dos caracteres que lo conforman subsidiaridad y fragmentariedad, que le imponen límites al ius puniendi del Estado.

\section{Subsidiariedad}

La subsidiariedad esencialmente consiste en recurrir al Derecho Penal como forma de control social solamente en los casos en que todas las otras formas de control son insuficientes, o sea, "cuando fracasan las demás barreras protectoras del bien jurídico que deparan otras ramas del derecho". Corresponde al Derecho Penal que de entre las demás ramas del ordenamiento jurídico la función de imponer las sanciones más fuertes como resultado de graves ataques a bienes jurídicos tutelados penalmente, es por ello que se le considera ultima ratio del sistema, en otras palabras "cuando el ataque no sea muy grave o el bien jurídico no sea tan importante, o cuando el conflicto pueda ser solucionado con soluciones menos radicales que las sanciones penales propiamente dichas, deben ser aquéllas las aplicables”.

No se puede utilizar al Derecho Penal como única solución ante los problemas sociales al cual se acude con inmediatez cuando se presenta un conflicto, sin haber utilizado antes los demás mecanismos. La norma penal debe intervenir solamente cuando hayan fracasado los

Revista de Ciencias Sociales - Número 70 (2017) - Universidad de Valparáíso - ISSN 0716-7725-Valparáiso, Chile 
demás controles, a través de medios desprovistos del carácter de sanción, las vías que atribuyen sanciones no penales, como la civil o administrativa, que de fallar plantearía la necesidad de acudir al Derecho Penal para sancionar el hecho.

Resulta al natural la adaptación del Derecho a las nuevas realidades para dar respuestas a los problemas que surgen con las trasformaciones sociales. El moderno Derecho Penal que de acuerdo con el criterio de Silva Sánchez ${ }^{1}$ lo distinguen dos características esenciales, "la combinación de la introducción de nuevos objetos de protección con la anticipación de las fronteras de la protección penal ha propiciado una transición rápida del modelo 'delito de lesión de bienes individuales' al modelo 'delito de peligro (presunto) para bienes supraindividuales". Sin dudas se evidencian los síntomas del expansionismo penal, expansionismo que se ha manifestado por considerar la protección de bienes jurídicos una exigencia para la penalización de determinados comportamientos contrariando la concepción clásica de este principio que es la no penalización de determinadas conductas. El bien jurídico ha dejado de ser límite del poder punitivo y se ha convertido en una justificación para emplearlo, pareciera que la protección de estos bienes es tarea exclusiva del Derecho Penal, que solo debiera intervenir cuando se han agotado otros medios de protección, por lo que se revela una infracción del principio de intervención mínima pues el bien jurídico es protegido por la ultima ratio del Derecho Penal ignorando por completo su carácter subsidiario.

\section{Fragmentariedad}

El carácter fragmentario consiste en limitar la actuación del Derecho Penal a los ataques más graves contra bienes jurídicos más relevantes. La actuación del Derecho Penal tiene como fundamento la protección de la sociedad, protección que se materializa en la tutela penal de bienes jurídicos, es decir, principio de protección de bienes

1. SILVA SÁNCHEZ, J. M.: "La Expansión del Derecho Penal: aspectos de la política criminal en las sociedades post industriales", Madrid: Editorial Civitas, 2001. Pág. 13.

Facultad de Derecho y Ciencias Sociales - Universidad de Valparaíso - Chile 
jurídicos, que son los intereses sociales que por su especial importancia merecen la protección penal, lo que no quiere decir que toda lesión a un bien jurídico deba ser sancionada por el Derecho Penal, la importancia que posea el bien jurídico y la violencia de la lesión son los dos elementos que se tienen en cuenta para su determinación.

La intervención penal se justifica a partir de la existencia tanto de desvalor de acción como de resultado, con relación a esto Roxin afirma que “(...) la realización del tipo presupone en todo caso y sin excepción tanto un desvalor de la acción como un desvalor del resultado". El desvalor de la acción es el límite entre una conducta delictiva y otra que no lo es atendiendo la especial peligrosidad social para los bienes jurídicos, mientras que el desvalor del resultado guarda relación con el bien jurídico y de la irreparabilidad del ataque a él dirigido depende la sanción.

El análisis de este principio a luz del expansionismo que ha experimentado el Derecho Penal nos demuestra que resulta contradictorio con su contenido si se tiene en cuenta que entre los rasgos del moderno Derecho Penal preventivo se encuentra la creación de los delitos de peligro abstracto, en los cuales se le otorga más relevancia al desvalor de la acción que al desvalor del resultado que no es una concreta puesta en peligro del bien jurídico. Urge determinar la necesidad de que estos delitos protejan bienes de trascendental importancia, cuya protección es indispensable para garantizar que no se efectúe su lesión.

\section{Principio de proporcionalidad}

El principio de proporcionalidad se fue introduciendo progresivamente, como tal, en las legislaciones penales a partir de la Revolución Francesa de 1789. Podemos encontrar sus antecedentes en lo proclamado en la Declaración de los Derechos del Hombre y del Ciudadano de 1789, donde se señala que la ley no debe establecer más penas que las estrictamente necesarias y que estas deben ser proporcionales al delito. En la obra cumbre de Beccaria, a la que nos referimos con anterioridad, encontramos entre otras concepciones en relación con la proporcionalidad de las penas, la que expresa que debe existir una proporción entre los delitos y las penas, $\mathrm{y}$ al respecto precisa que si se destina una

Revista de Ciencias Sociales - Número 70 (2017) - Universidad de Valparáíso - ISSN 0716-7725-Valparaíso, Chile 
pena igual a dos delitos que ofenden desigualmente a la sociedad, los hombres no encontrarán un obstáculo más fuerte para cometer el mayor cuando éste les acarree mayores ventajas y concluye afirmando que uno de los mayores frenos del delito no es la crueldad de las penas, sino su infalibilidad.

De las concepciones de Beccaria sobre la proporcionalidad se aprecian dos vertientes: que la pena ha de ser necesaria, que se materializa en la idea de que la pena no ha de ir más allá de lo que es necesario para cumplir un fin, y por otra parte, la pena ha de ser infalible, referida a la necesidad de que en la fase de ejecución hay que garantizar su cumplimiento efectivo.

Entre las diferentes técnicas de anticipación de la tutela, usadas por el Derecho Penal en los tiempos actuales, se encuentran los delitos de tentativa, específicamente de una de sus modalidades los delitos de emprendimiento o de empresa. En estas figuras delictivas la tentativa recibirá la misma pena que el delito consumado, al no aplicarse la rebaja que se dispone en el artículo 12.5 del Código Penal cubano, y por tanto la exclusión de la pena por el desistimiento, o el arrepentimiento en los casos de tentativa regulados el artículo 13.1, de lo que puede interpretarse que hay cierto desapego al principio de proporcionalidad o prohibición del exceso pues tanto la realización de los actos delictivos como el intento de realizarlos se penan con la misma sanción. Cabe preguntarse si está yendo la pena más allá de lo necesario para cumplir su fin.

Debemos tener presente lo expresado por Ferrajoli²:

(...) si el Derecho Penal es el remedio extremo, deben reducirse a ilícitos civiles todos los actos que de alguna manera admiten reparación, y a ilícitos administrativos todas las actividades que violan reglas de organización de aparatos, o normas de correcta administración, o que produzcan daños a bienes no primarios, o que sean solo abstractamente presumidas como peligrosas.

La justicia es el pilar más sólido que pude tener cualquier sistema, por lo que nuestro sistema penal luego de contrariar los principios

2. LÓPEZ CELEIRO, I.: "Los delitos de peligro: ¿Desafío o necesidad para el Derecho Penal contemporáneo?”. En: Boletín ONBC, Ediciones ONBC, No 42, julio-diciembre 2010. Pág. 36.

Facultad de Derecho y Ciencias Sociales - Universidad de Valparaíso - Chile 
penales debe estar en consonancia con ellos, aunque esto represente un reto en los tiempos actuales. El primer paso debe ser reducir los tipos penales que representan una anticipación de la tutela penal, dentro de estos principalmente los de peligro abstracto que poseen una antijuricidad más formal que material, pues no es necesario demostrar que el bien jurídico ha sido puesto efectivamente en peligro de ser lesionado. Deben pasar al ámbito del Derecho administrativo muchas de las conductas de peligro abstracto para las que la ley establece sanciones mínimas, en los casos en que por su importancia para la sociedad moderna se requiera que continúen en el Código Penal debieran configurarse como delitos de peligro concreto de forma que sea imprescindible la producción del daño para el bien jurídico protegido por el tipo, deben ser objetos concretos que permitan la determinación de su puesta en peligro en la situación específica, quedando solo en nuestro código los delitos de peligro abstracto necesarios.

\subsection{Derecho Penal de riesgo y adelanto de la tutela penal}

La expresión "sociedad de riesgo", referida a las sociedades modernas llenas de nuevas fuentes de peligro, fue introducido por el sociólogo alemán Ulrich Beck en 1986 en su libro "Risikogesellschaft". Con posterioridad en la obra de Prittwitz "Derecho Penal y riesgo" (StrafechtundRisiko", 1993), es donde por vez primera se trata la cuestión de hasta qué punto el Derecho Penal está en condiciones de hacer frente con su tradicional instrumento liberal ajustado al Estado de Derecho a los modernos riesgos de la vida como pueden ser los de tipo atómico, químico, ecológico y de técnica genética. Actualmente se discute el modo en que este debe funcionar frente a los nuevos riesgos de la sociedad, que ha creado un Derecho Penal preventivo que interviene en momentos muy anteriores a la lesión del bien jurídico.

Lo que conocemos como "Derecho Penal de la sociedad de riesgo" o "Derecho Penal de riesgo" se entiende como:

(...) un Derecho Penal adaptado a las nuevas exigencias planteadas por la sociedad moderna caracterizada como una sociedad de riesgo, amenazada por nuevas fuentes de peligro dependientes de la manipulación humana, como la explotación de la energía nuclear o la

Revista de Ciencias Sociales - Número 70 (2017) - Universidad de Valparáíso - ISSN 0716-7725-Valparáiso, Chile 
industria química, y para cuyo control resultarían insuficientes las categorías jurídico - penales tradicionales ${ }^{3}$.

En específico, el Derecho Penal del riesgo se manifiesta en un brusco cambio de los criterios de imputación propios del Derecho Penal liberal, la ruptura del principio de taxatividad de los tipos penales, y en la extensión desmedida del Derecho Penal, en gran medida a través de la creación de bienes jurídicos universales y con los delitos de peligro abstracto al frente de la cruzada contra los riesgos. Lo curioso del caso es que la propia tendencia entraña el riesgo de politización del Derecho Penal, su utilización en el debate político ante riesgos de grandes dimensiones como vía de solución que demuestra que se es consciente de un problema en lugar de realizar planes y poner el presupuesto en función de proyectos políticos a largo plazo, la hace bastante rentable.

Esta tendencia expansiva comenzó a manifestarse con nitidez a partir de los años setenta del pasado siglo, originándose por dos razones fundamentales:

- La primera fue el período de mayor elevación del terrorismo, ámbito en el cual el Derecho Penal interviene cada vez más adelantadamente ya sea mediante la punición de actos preparatorios, o la creación de delitos de tentativa.

- La segunda razón fue el incremento del desarrollo industrial y tecnológico y paralelamente los avances de la técnica en las diferentes ramas lo que representa una significativa mejoría para las condiciones de vida pero requieren la necesidad de afrontar los nuevos riesgos que estas traen consigo, y las consecuencias de determinadas conductas como pueden ser por ejemplo las desarrolladas durante el transporte de sustancias explosivas o radioactivas. El desarrollo con sus ventajas enormes, creó también fuentes de peligro de las mismas dimensiones y con un elevado potencial destructivo, de difícil manejo como es el caso de la energía nuclear.

3. SÁNCHEZ GARCÍA DE PAZ, M. I.: El moderno Derecho Penal y la anticipación de la tutela penal, Secretario de Publicaciones e Intercambio Científico, Universidad de Valladolid, España, 1999. Pág. 13.

Facultad de Derecho y Ciencias Sociales - Universidad de Valparaíso - Chile 
Otra razón en los casos no relacionados con las mencionadas fuentes de peligro de gran potencia, es el otorgamiento de mayor protección a bienes jurídicos como la vida que requieren un adelantamiento de su protección penal para evitar las conductas que la han lesionado con efectividad.

Es en estas condiciones que se produce la expansión del Derecho Penal mediante la anticipación de la tutela, la doctrina alemana se refiere a este fenómeno como Vorfeldkcriminalizierumg (criminalización en el ámbito previo). Según Fuentes Osorio4 "El término «anticipación penal» se refiere a un modo de actuación penal ilegítima porque no respeta los límites impuestos por el principio de ofensividad: se prevé una intervención penal contra conductas que no representan un ataque con suficiente entidad objetiva al bien jurídico tutelado”.

Los autores coinciden con el criterio de Sánchez García de Paz ${ }^{5}$ “(...) cuándo podemos entender que ha tenido lugar una anticipación de la tutela penal. Tarea difícil, pues, como se adivina, la respuesta será diferente en el contexto de cada concepción del Derecho Penal. En el eje del debate se encuentra la cuestión de la legitimación misma del ius puniendi, de su fundamento y límites. Es por ello una cuestión ligada al contraste entre las diferentes orientaciones de la dogmática penal, a cada concepción del injusto y de la pena", pero pese a la variabilidad del término la entiende como la intervención punitiva adelantada que tiene clara expresión en el movimiento legislativo penal mediante el empleo por el legislador de diferentes técnicas y procedimientos que posibilitan la expansión de la tutela penal hacia nuevos ámbitos o ámbitos previos, lo que constituye un rasgo del Moderno Derecho Penal.

Es preciso aclarar cuál es el núcleo básico del Derecho Penal al que nos estamos anticipando, constituido por las conductas a cuya sanción está dirigido original y principalmente el poder punitivo.

4. FUENTES OSORIO, J. L.: "Formas de anticipación de la tutela penal”. En: Revista Electrónica de Ciencia Penal y Criminología [En línea] Disponible en http://criminet.ugr.es/recpc/08/recpc08-08.pdf.

5. SÁNCHEZ GARCÍA DE PAZ, M. I.: El moderno Derecho Penal y la anticipación de la tutela penal, Secretario de Publicaciones e Intercambio Científico, Universidad de Valladolid, España, 1999. Pág. 12.

Revista de Ciencias Sociales - Número 70 (2017) - Universidad de Valparáíso - ISSN 0716-7725-Valparaíso, Chile 
Inicialmente el Derecho Penal estuvo orientado a sancionar conductas que provocaran una lesión y luego se fue extendiendo a la protección de bienes jurídicos ante los comportamientos que lo pusieran en peligro concreto y finalmente en peligro abstracto, por tanto se entiende que el núcleo del Derecho Penal está conformado por aquellas conductas que lesionan el bien jurídico y cualquier otra conducta que esté próxima a dicha lesión forma parte de su ámbito previo, la intervención punitiva en él, es resultado del adelanto de la tutela penal.

En consecuencia las esferas de la Parte Especial más afectados con esta tendencia de forma mundial son los delitos contra la seguridad del Estado, en particular los referidos al terrorismo, el Derecho Penal Económico, el relativo al Medio Ambiente y los delitos asociados al ejercicio de actividades peligrosas, entre otros.

En el caso de nuestro país que ha sido amenazado y agredido desde que se declarara el carácter socialista de nuestra revolución, por las diferentes administraciones de los Estados Unidos, la seguridad nacional constituye sin dudas una prioridad y la importancia de ese bien jurídico esencial para que el Estado Cubano pueda proteger otros bienes justifica la anticipación de la tutela penal en este ámbito. Hemos sido víctimas de actos de terrorismo que le han costado la vida a deportistas, jóvenes y niños, factor determinante de que la regulación de estas ilícitos se haga en un cuerpo legal independiente del Código Penal. La Ley 93/2001se promulga en el año que el mundo conociera un acto de terrorismo sin precedentes, el atentado contra las Torres Gemelas en suelo norteamericano el 11 de septiembre de 2001.

El medio ambiente es un bien jurídico colectivo que protegen algunos ordenamientos jurídico-penales, en los que se establecen además circunstancias específicas agravantes de la responsabilidad penal ambiental como, por ejemplo:

- La generación de un daño en los delitos de riesgo, o la derivación como consecuencia del delito de la muerte de una persona o la generación de un daño o peligro para la salud de las personas.

- La comisión de delitos en ciertas circunstancias, entre las que podríamos citar: la violación de licencias ambientales u otras

Facultad de Derecho y Ciencias Sociales - Universidad de Valparaíso - Chile 
autorizaciones, la realización clandestina de actividades, o la omisión o tergiversación de la información ambiental por la autoridad de control para autorizar la actividad.

- La contaminación del agua y el aire en zonas densamente pobladas o degradación de sistemas dentro de áreas protegidas.

- La reiteración y la reincidencia.

No sucede así en nuestro país, donde los delitos ambientales carecen de sistematicidad en el Código Penal, encontrándose dispersos en distintas familias de delitos. Si bien muchas de las figuras delictivas constituyen delitos de peligro las sanciones previstas son de multa y de privación de libertad que en su mayoría no son superiores a un año. La autora piensa que la intervención penal en este ámbito, debido a la importancia del bien jurídico es acertada, es inexistente la anticipación desmedida, lo que no impide que de realizarse transformaciones legislativas se estructure mejor lo relativo a los delitos ambientales.

Los últimos años en nuestro país han estado marcados por un período de auge del Derecho Penal Económico, que trasciende a los planes de estudio, cursándose de forma independiente. La Economía Nacional es un bien jurídico de colosal importancia que adquiere todavía más en un país subdesarrollado como el nuestro, el avance doctrinal de esta especialidad no se refleja en el movimiento legislativo. Pese a que podemos encontrar en el título de Delitos contra la Economía nacional, la utilizada técnica de delitos de peligro abstracto, no estamos en presencia de la desmedida expansión de la tutela penal que destaca en otros ordenamientos jurídicos penales.

Las transformaciones que se han estado produciendo en el modelo económico cubano, caracterizadas por el aumento de las actividades privadas o de índole particular del que resulta necesariamente mayor registro, intervención, diligencia y control de los recursos económicos, financieros y materiales del Estado, requieren de una prioridad de los sujetos y agentes económicos y a la par una respuesta adecuada del ordenamiento jurídico-penal. La criminalidad surgida en este contexto demanda profundizar en el estudio del Derecho Penal económico.

En la actualidad las figuras delictivas van en aumento y al unísono se agrava la sanción de muchas de las ya existentes, el legislador

Revista de Ciencias Sociales - Número 70 (2017) - Universidad de Valparáíso - ISSN 0716-7725-Valparáiso, Chile 
recurre con mayor frecuencia a los delitos de peligro, mientras específicamente se evidencia el aumento de los delitos de peligro abstracto, cada vez se anticipa más la intervención penal en la misma medida que el Derecho Penal va extendiendo las áreas de punibilidad valiéndose para ello de diferentes técnicas.

\subsection{Técnicas de anticipación de la tutela penal}

El expansionismo del Derecho Penal contemporáneo se ha caracterizado por el uso de diferentes técnicas que constituyen un conjunto de procedimientos y recursos que permiten anticipar la intervención punitiva y forman parte de lo que se conoce en la actualidad como "Derecho Penal de la sociedad de riesgo" o "Derecho Penal de riesgo", entre las que vale la pena mencionar los delitos de peligro, de tentativa y de emprendimiento, la punición como delitos independientes de actos preparatorios, los delitos de intención sin lesión de un bien jurídico y la creación de bienes jurídicos colectivos.

\section{Delitos de peligro}

Los delitos de peligro son aquellos en que la acción o el desvalor antijurídico ocasionan un perjuicio posible al bien jurídico protegido. En la doctrina existen diferentes clases de delitos de peligro, en atención al número de titulares del bien jurídico y el riesgo que este corre son delitos de peligro general o común y delitos de peligro particular e individual y los delitos de peligro abstracto y los delitos de peligro concreto respectivamente, en esta última clasificación profundizaremos más adelante.

Delitos de peligro individual son aquellos que se tipifican para proteger contra la amenaza a la vida o la salud de una persona, ejemplo, el abandono de menores previsto en el Artículo 271.4 de la Ley 62/87. Son delitos de peligro común o general los que se refieren a situaciones en que se pone en riesgo, la vida, salud o propiedad de un número indeterminado de personas o cosas, ejemplo la Propagación de epidemias regulada en el Artículo 187 de nuestro Código Penal que forma parte de los delitos Que atentan contra la Salud Pública.

Facultad de Derecho y Ciencias Sociales - Universidad de Valparaíso - Chile 
La técnicas de anticipación de la respuesta penal...

\section{Delitos de peligro abstracto y delitos de peligro concreto}

En los de peligro concreto se exige para la configuración de la figura delictiva la existencia de una situación específica de peligro para el bien jurídico, que debe ser probada pues es parte integrante de los elementos constitutivos del delito, constituyendo elementos relevantes de su estructura el nexo causal entre la conducta peligrosa y el bien jurídico protegido y el juicio acerca del peligro.

En estos delitos se manifiesta una doble tutela del bien jurídico pues al configurar determinado delito de peligro concreto, convierte en bien jurídico la seguridad de otro bien jurídico, al vulnerarse la seguridad de ese bien jurídico se ha lesionado por tanto el bien jurídico específicamente protegido en el delito de peligro concreto. Ejemplo de esto es el artículo 185-b regulado en el Título III - Delitos Contra La Seguridad Colectiva, Capítulo IV- Infracciones de las normas referentes al uso y conservación de las sustancias radiactivas u otras fuentes de radiaciones ionizantes. Al ponerse en riesgo la seguridad de ese bien jurídico (la vida, la salud de las personas o sus bienes) se ha producido la lesión del bien jurídico protegido específicamente en el delito concreto o sea la Seguridad colectiva. La ley ha creado un nuevo límite colocado en un momento anterior al daño efectivo, anticipa la protección de la vida, la salud de las personas y sus bienes, aunque como lo expresa el artículo explícitamente no se produzcan daños, se ha puesto en peligro la seguridad colectiva, que es lo realmente dañado.

En los de peligro abstracto no se exige que la conducta haya provocado un peligro efectivamente pues la sola realización del hecho pone en peligro el bien jurídico según lo entiende el legislador. La ley incrimina estas acciones con independencia de una lesión efectivamente destructiva del bien jurídico y sin que ocasionen la puesta en peligro concreto de ese bien jurídico, son sancionables porque generalmente poseen una idoneidad genérica para crear peligros y causar daños, quizás en este particular radica la clave de su reiterativa utilización por lo que al decir de algunos se ha convertido en "el hijo predilecto del legislador".

Ejemplo de ello es el artículo 199.1 donde se sanciona la conducta descrita que es alterar los exámenes practicados en el laboratorio sin que para ello deba concurrir otra circunstancia, por sí solo el compor-

Revista de Ciencias Sociales - Número 70 (2017) - Universidad de Valparáíso - ISSN 0716-7725-Valparaíso, Chile 
tamiento es punible porque pude causar daño y poner en peligro el bien jurídico protegido que es la seguridad de la salud, aunque en la realidad no se produzca daño ni peligro para la salud de las personas.

Estos delitos han sido blanco de abundantes críticas primeramente por ser contrarios a lo que algunos autores llaman "principio de ofensividad o lesividad", que está estrechamente ligado a la antijuricidad, rasgo del delito que exige que todos los comportamientos delictivos sean antijurídicos formalmente, entendiéndose como acciones contrarias al ordenamiento jurídico, (desvalor de la acción), desaprobadas por este y materialmente, estas acciones tienen que ofender al bien jurídico que la norma protege ya sea lesionándolo o poniéndolo en peligro (desvalor del resultado). La crítica no radica en que no exista en ellos un desvalor del resultado, lo censurable es que el moderno Derecho Penal tiende a conceder mayor importancia al desvalor de la acción o lo que es igual, a la peligrosidad social, al potencial lesivo que genera. Con anterioridad al tendiente adelanto de la barrera punitiva, era indiscutible el vínculo indisoluble entre la protección de bienes jurídicos y la antijuricidad, siendo necesario que los delitos de peligro abstracto debieran proteger un bien jurídico e implicar la posibilidad de su puesta en peligro, pero en la actualidad estos tipos penales constituyen la justificación ante la necesidad de anticipar la tutela y la urgencia de proteger un bien jurídico, legitimando los delitos de peligro.

Otro aspecto discutible resulta, el de la prueba de la producción de un resultado de peligro, que al no ser necesaria hace escasas las posibilidades de defensa y propicia la desaparición de la determinación de la relación de causalidad entre el acto realizado por la persona y el resultado. Es también objeto de censura el hecho de sancionar a la persona por una conducta, aun cuando el peligro que fue presumido

6. Desde la perspectiva del principio de lesividad del bien jurídico, también denominado de exclusiva protección de bienes jurídicos, tiene una doble función, actúa como fundamento y como límite al poder punitivo del Estado. Los bienes jurídicos protegen los derechos individuales y colectivos necesarios para la pacífica convivencia de los miembros de la sociedad y el ejercicio de sus derechos y libertades, por lo que son instituidos en el contexto político-social. Actualmente goza de gran aceptación en la doctrina actual y encuentra reconocimiento expreso en Códigos penales como el salvadoreño.

Facultad de Derecho y Ciencias Sociales - Universidad de Valparaíso - Chile 
legalmente no se haya producido en el caso concreto. Los delitos de peligro han aumentado las posibilidades de que se produzcan conflictos entre los bienes jurídicos colectivos y los de carácter individual cuando en la realización del comportamiento socialmente peligroso, tipificado por el hecho de serlo como delito se produce además un resultado de daño. En situaciones similares es obligado preguntarse qué es lo que el Derecho Penal debe sancionar si el peligro realizado y también el resultado lesivo ocasionado, dependiendo la respuesta a esta interrogante de las posiciones que sean adoptadas en cuanto a la autonomía de los bienes jurídicos colectivos, respecto a los individuales.

Estamos en presencia de una situación de este tipo en el caso del delito de portación y tenencia ilegal de armas y el empleo de esa arma para cometer alguno de los delitos contra la vida y la integridad corporal, expuesto con mayor profundidad en el artículo: Los delitos de peligro: Desafío o necesidad para el Derecho Penal contemporáneo? Según este, en relación con lo anterior, la Fiscalía se ha pronunciado por imputar ambos delitos, entendiendo que son dos acciones independientes aun cuando el Tribunal manifestó un cambio de opinión con respecto a esta doble imputación.

Hasta el año 2001 el Tribunal Supremo Popular sostuvo la opinión de que se trataba de un concurso real y no de uno aparente de normas, en una Comunicación "Acerca de la imputación del delito de portación y tenencia ilegal de armas cuando concurre con otra tipicidad", emitida el 29 de octubre de 2002 la Dirección de Procesos Penales de la Fiscalía General de la República, explica esta posición al expresar que la jurisprudencia había considerado que dicho delito existía y se consumaba con anterioridad a la ejecución del delito lesivo en el que se utilizaba el arma, lo que demostraba que el fin de la portación ilícita del arma era la comisión del acto delictivo, razón por la cual ambos delitos debían sancionarse de forma independiente, al no darse entre ellos una relación de medio a fin porque excepto un caso muy especial "cualquier delito podría cometerse sin el uso de un arma o instrumento utilizado como tal". Lo anterior se aprecia en fragmentos de los Considerandos de las Sentencias N ${ }^{\circ} 1095$ de 15 de octubre de 1988, $\mathrm{N}^{\circ} 5265$ de 19 de septiembre del 2000, No 5281 de 19 de diciembre de 2000, todas del Consejo de Gobierno del Tribunal Supremo Popular.

Revista de Ciencias Sociales - Número 70 (2017) - Universidad de Valparaíso - ISSN 0716-7725-Valparaíso, Chile 
Desde el 2001 comenzó a evidenciarse un cambio de opinión entre los jueces del mencionado órgano, quienes se muestran a favor de que el delito de portación y tenencia ilegal de armas o explosivos, no se califique de forma independiente cuando se trate de cuchillos $\mathrm{u}$ otros instrumentos punzantes, cortantes o contundentes, que se encuentre en poder la persona porque esta tiene la intención de cometer un hecho delictivo. Las razones que motivan este cambio son primeramente que no debe sancionarse el delito de lesión y además sus actos preparatorios, que en estos casos sería la tenencia de los mencionados instrumentos y la segunda es que la conducta de conseguir un instrumento para emplearlo en la ejecución de otro delito, es absorbida por aquel que con el uso del mentado instrumento se cometía o se comenzaba a ejecutar (tentativa), entendiéndose que en estos supuestos estamos en presencia de un concurso aparente de normas penales. Empero este criterio no se hizo extensivo de acuerdo con lo expresado en la mencionada Comunicación de la Fiscalía General al hecho en que para los mismos fines se porte un arma de fuego sin licencia, admitiéndose en este particular la calificación y sanción independiente, por la propia ilicitud del arma. Este cambio de opinión se manifiesta en las siguientes sentencias del Consejo de Gobierno del Tribunal Supremo, $\mathrm{N}^{\circ} 2965$ del 4 de julio del 2005, $\mathrm{N}^{\circ} 4566$ de 14 de octubre de 2005, $\mathrm{N}^{\mathrm{o}} 2660$ de 16 de junio de 2005 y No 4083 de 22 de noviembre de 2002.

La Dirección de Procesos Penales de la Fiscalía, aun teniendo conocimiento del cambio que ha ocurrido en el criterio de los jueces de la Sala Penal del Tribunal Supremo, en la mencionada Comunicación manifiesta un criterio opuesto al disponer que los fiscales continúen imputando el delito de portación y tenencia ilegal de armas, siempre que la persona tenga en su poder cualquier instrumento cortante, punzante o contundente para utilizarlo en la comisión de cualquier acto antisocial o un arma de fuego sin tener licencia para ello; estableciendo una excepción en su actuar cuando disponen que no se recurra más a casación ni se apele en su caso, si el Tribunal de la instancia correspondiente absuelve por este cuando se refiere a instrumentos cortantes, punzantes o contundentes, por ser mínima la probabilidad de que esa impugnación tenga un resultado favorable a sus propósitos, a la vez que orienta que siempre se recurra en el caso de que la Sala de

Facultad de Derecho y Ciencias Sociales - Universidad de Valparaíso - Chile 
juicio no acepte la clasificación por la tenencia o portación de un arma de fuego sin licencia, con la que se cometa otro delito. La posición de la Fiscalía parece explicarse en un material sobre el delito de portación y tenencia ilegal de armas emitido igualmente por la Dirección de Procesos Penales de la Fiscalía General de República del año 2000 pues basándose en la separación temporal de ambos supuestos se manifiesta un concurso real de infracciones, lo que resulta cierto, lo contradictorio de este caso es que aun cuando el delito lesivo tenga como circunstancia agravante, el empleo de un arma deba imputarse también el de portación y tenencia ilegal de armas y explosivos, pues el delito se comete desde el momento de la adquisición del arma, ya sea antes o después de haberla utilizado para ejecutar el acto delictivo.

Los autores consideran que si una persona porta un arma cortante, punzante o contundente, lo que configura un delito de peligro y con ella ejecuta un acto delictivo que lesione un bien jurídico en cuya figura se contiene como circunstancia de agravación el empleo de un arma como pueden ser los delitos de robo con violencia (artículo 327.1.4b), amenazas (artículo 284.1.2) y desórdenes públicos (artículo 200.1.3) no debe apreciarse por la misma arma otro delito de portación, pues eso sería considerar dos veces la misma circunstancia lo cual va en contra de lo regulado en el artículo 47.2 del Código Penal cubano, que prohíbe que la circunstancia que es elemento constitutivo de un delito se considere así mismo circunstancia agravante de la responsabilidad penal, por lo que si realizamos una interpretación correcta de la norma entenderíamos prohibida la apreciación de un mismo hecho dos veces. Debe entenderse que en los casos mencionados, tiene lugar un concurso aparente de normas penales que se soluciona aplicando la consunción como principio pues el delito de peligro es absorbido por el de lesión que lo contiene como circunstancia de cualificación.

En la práctica el Tribunal Supremo en muchas de sus sentencias, fundamentalmente las referidas al robo con violencia cuando el arma se emplea en una figura agravada de un delito, el acusado la portaba precisamente para la comisión del delito, no debe sancionarse también por la portación y tenencia ilegal de armas.

Revista de Ciencias Sociales - Número 70 (2017) - Universidad de Valparáíso - ISSN 0716-7725-Valparaíso, Chile 


\section{Delitos de tentativa}

Los conocidos como delitos de tentativa son aquellos en los que se sanciona de forma independiente ese grado de ejecución del delito, cuya producción equivale a la consumación del mismo, si consideramos en ellos únicamente su realización representan delitos de peligro, diferenciándolos de los delitos de peligro comunes el elemento subjetivo, pues en estos últimos el dolo se limita a la puesta en peligro del bien jurídico, mientras que en los de tentativa, entre los que se incluyen los de emprendimiento, el dolo se extiende a la lesión del bien jurídico, la persona intenta hacer algo que finalmente no consigue, con lo que ya se tipifica el delito pero su intención iba más allá del resultado obtenido.

Una modalidad especial de los delitos de tentativa la constituyen los delitos de emprendimiento o de empresa pues en ellos una tentativa es tipificada de forma autónoma, en una figura de la parte especial del Derecho Penal, imponiendo por ella la misma sanción que se aplicaría en el caso de un delito consumado. En nuestro Código Penal pueden encontrarse varios ejemplos de estos delitos de emprendimiento: el delito de salida ilegal del país (artículo 216.1) que sanciona igualmente al que "salga o realice actos tendentes a salir", el delito de contrabando que afecta la economía nacional (artículo 233 a) y b)), se refiere indistintamente al que sin cumplir las disposiciones legales en el primer supuesto "introduzca o intente introducir en el país objetos o mercancías" y en el segundo "extraiga o intente extraer del país objetos o mercancías", el delito de lavado de dinero establece la misma sanción tanto para quien adquiera, convierta o trasfiera recursos, bienes o derechos relativos a ellos como para quien intente realizar estas acciones.

No se duda de la necesidad de penar la tentativa como alternativa para evitar que la consumación del delito impida su efectiva represión como es el caso del delito de extracción ilegal de bienes de patrimonio cultural del país regulado en el artículo del Código Penal pues en este particular existe la posibilidad de que no pueda ser sancionada la persona una vez que extraiga los bienes y se encuentre fuera del país, mientras que en otros, lo expuesto anteriormente no resulta un argumento sólido como es el caso de la evasión fiscal en el artículo 343.1, en los que si se consuma se puede castigar, de modo que la tentativa de su realización

Facultad de Derecho y Ciencias Sociales - Universidad de Valparaíso - Chile 
podría ser sancionada, aplicando lo regulado en la Parte Especial de nuestro Código Penal. Es aquí donde vale hacer un paréntesis. La autora manifiesta que se evidencia una desmedida intervención del Estado para adelantar la punibilidad cuando ante cualquier situación debiera tenerse en cuenta la particular relevancia de los bienes jurídicos que se protegen como condición para sancionar una tentativa como un delito independiente consumado.

En estos delitos lo que se anticipa en sentido estricto, es la consumación de los mismos y no los límites de punibilidad, pues de no existir dichos comportamientos continuarían sancionándose, en principio como tentativa del delito, pero indiscutiblemente traen consigo una mayor sanción de las acciones ejecutivas que intentan la perpetración del delito, sobre todo en los delitos de emprendimiento donde la tentativa recibirá la misma pena que el delito consumado, no siendo aplicable la rebaja que recoge el artículo 12.5 , ni la exclusión de la pena por desistimiento o el arrepentimiento en los casos de tentativa que regula el artículo.

\section{Delitos de preparación o actos preparatorios}

Los delitos de preparación son comportamientos que exteriorizan la idea de cometer un delito, sin comenzar su ejecución mediante la preparación de actos idóneos para ello (actos preparatorios) que son penalizados de forma independiente.

Las conductas de conspiración, o sea la unión de voluntades en función de la ulterior ejecución del hecho delictivo, son sancionables en este ámbito. En nuestra legislación podemos encontrar varios ejemplos de delitos de preparación como la asociación para delinquir (regulado en el artículo 207.1), el solo hecho de asociarse es sancionable aunque nunca se lleguen a realizar efectivamente los delitos; la portación y tenencia ilegal de armas y explosivos (comprendido en el artículo 214) se sanciona al que porte o tenga en su poder un puñal, punzón, navaja, cuchillo o cualquier instrumento cortante, punzante o contundente si las circunstancias en que se le ocupa dicha arma

demuestra que va a ser usada con fines delictivos o antisociales; la fabricación, introducción o tenencia de instrumentos destinados a 
falsificar (tratado en el artículo 259.1)se sanciona la fabricación o introducción en el país de instrumentos destinados a falsear, aunque no se haya realizado dicha falsificación y por último la tenencia, fabricación y venta de instrumentos idóneos para ejecutar el delito de robo ( previsto en el artículo 330.1) donde no se requiere que dichos instrumentos se empleen para ejecutar un robo la sola fabricación o tenencia de estos es castigada.

Estos delitos nos demuestran el giro que se ha efectuado de la tutela tradicional de bienes jurídicos a estas conductas preparatorias de otro comportamiento delictivo que han sido configuradas como delitos independientes, utilizando diferentes formas. Las más comunes son castigadas por la sola posesión de objetos que frecuentemente son utilizados para cometer alguna clase de delitos o la sola manifestación de voluntad de realizar hechos delictivos a través de una asociación ilícita, su criminalización de forma autónoma, en momentos anteriores a lesión del bien jurídico, se debe al interés del legislador por sancionar momentos del comportamiento delictivo que preparan la realización de comportamientos de igual naturaleza, pues entiende que dichos actos son muy peligrosos para el bien jurídico protegido en virtud de la importancia del bien. Existan casos en los que no se utiliza exclusivamente los actos preparatorios como grado de desarrollo del delito, muchos de los delitos de peligro se forman para configurar estos actos como son el de tenencia de armas y el de instrumentos para falsificar.

Lo controvertible en estos supuestos es la existencia de una efectiva protección de bienes jurídicos, pues el objeto protegido no sufre de forma directa el peligro de ser lesionado. Al tipificarse independientemente ciertos actos preparatorios el legislador amplió los ámbitos de objeto de la intervención penal adelantándola cuando debiera ser preciso respetar ciertos límites. La autora estima necesario que al emplearse como técnica los delitos de preparación, su utilización debe basarse no solo en la importancia del bien jurídico protegido también en que las conductas sean especialmente peligrosas en el campo previo a la tentativa, estableciéndose para estos delitos sanciones inferiores a las que son impuestas en el caso de que se efectuaran las tentativas de los delitos que preparan.

Facultad de Derecho y Ciencias Sociales - Universidad de Valparaíso - Chile 


\section{Delitos de intención sin lesión del bien jurídico}

Estos delitos son aquellos cuyo elemento subjetivo trasciende al dolo, en cuanto el autor persigue un fin, determinado en el tipo que no requiere la realización del fin para configurar la figura delictiva.

Únicamente los delitos de intención cuya ejecución no lesiona un bien jurídico, constituyen técnicas de anticipación de la punibilidad. En los ejemplos que se expondrán más adelante comprobamos que se castiga la intención, la finalidad que se persigue al cometer el comportamiento delictivo, aunque estos fines nunca se logren. Nuestro Código Penal varios ejemplos como son: el delito de pesca ilícita (establecido en el artículo 242.1) que sanciona la penetración en aguas territoriales o en la Zona Económica de la República por parte de un extranjero sin la debida autorización con el fin de practicar la pesca aunque nunca llegue a realizarla, el delito de falsificación de moneda (regulado en el artículo 248.1-ch) que penaliza la tenencia de monadas falsas en circunstancias que indiquen son para la expedición o circulación aun cuando no lleguen a expedirse o a circular y el delito de difusión de noticias falsas contra la paz internacional (previsto en el artículo 115) que sanciona a toda persona que difunda noticias falsas con el propósito de perturbar la paz internacional o de poner en peligro el prestigio del Estado cubano o sus buenas relaciones con otro Estado, aunque la finalidad no se consiga.

\section{Creación de bienes jurídicos colectivos}

La creación de bienes jurídicos colectivos es una técnica dirigida a la protección de aquellos bienes en que se configuran delitos de peligro, generalmente del tipo que no requiere la concreción del mismo, facilitándose la prueba del delito, la expansión del Derecho Penal hacia la producción de dichos bienes y la anticipación de la tutela penal a la par.

La creación de bienes jurídicos colectivos responde a la tendencia político criminal actual de proteger los bienes jurídicos individuales de forma preventiva mediante delitos de peligro abstracto, que han sido objeto de muchos críticas por lo que se asumió la opción de crear un

Revista de Ciencias Sociales - Número 70 (2017) - Universidad de Valparáíso - ISSN 0716-7725-Valparaíso, Chile 
bien jurídico colectivo en el ámbito previo del bien jurídico individual, de manera que los delitos de peligro lesionen al bien colectivo, lo cual representa una estrategia para silenciar las críticas que suscitan los delitos de peligro abstracto, cuando realmente continúan siendo delitos que protegen el bien jurídico individual que ahora se ve doblemente protegido por otro bien jurídico y en ocasiones siguen siendo delitos de peligro en relación con el bien jurídico colectivo.

Podemos identificar los bienes jurídicos colectivos por ser intereses que necesitan de protección penal debido a su elevada importancia para la sociedad, pero su titular no recae en el individuo, sino en la sociedad y el Estado. Comunes ejemplos en las legislaciones penales actuales y específicamente en la nuestra son: la seguridad del tránsito (Delitos contra la Seguridad del tránsito, Capítulo III, Título III, Libro II, Parte Especial);la salud pública (Delitos contra la Salud Pública, Capítulo Título III, Libro II, Parte Especial) ; la integridad del patrimonio histórico y artístico (Delitos contra el Patrimonio Cultural, Título VI, Parte Especial ); la seguridad en el trabajo (Delitos contra los Derechos Laborales, Título X, Parte Especial) y el medio ambiente, bienes que se ubican en el marco del Derecho Penal Socioeconómico, relacionados con el buen funcionamiento del sistema crediticio y del mercado, así como a los intereses del colectivo de los consumidores.

La protección de estos bienes tiene como objetivo mantener las condiciones de seguridad para que se desarrollen tanto los bienes macrosociales como los individuales entre los cuales existe una relación, pues quien contamina el medio ambiente pone en condiciones de peligro la vida y la salud de las personas. Es desde esta óptica que podemos decir que tienen una doble perspectiva, individual y colectiva, funcionando a modo de complemento de un bien jurídico individual de gran importancia en tanto anticipa su protección ante nuevas fuentes de riesgo por lo que se les conoce como "intereses funcionales e instrumentales" o "bienes jurídicos de ámbito previo". Generalmente los delitos que protegen bienes jurídicos individuales representan un peligro concreto pues la puesta en peligro del bien jurídico debe ser comprobada conforme a la realidad objetiva, mientras lo común es que los delitos de peligro abstracto se refieran a bienes jurídicos colectivos que tienen como propósito prevenir el peligro general que puede afectar la seguridad

Facultad de Derecho y Ciencias Sociales - Universidad de Valparaíso - Chile 
colectiva e indirectamente a los bienes jurídicos individuales, pero sin que ese peligro deba materializarse para configurar la figura delictiva, lo que no representa la inexistencia de delitos de peligro concreto que protejan bienes colectivos como los delitos de estragos regulados en los artículos 174.1 y 174.2. Lo preocupante es que una elevada creación de bienes jurídicos colectivos puede traer consigo puramente la protección de funciones sociales, cambiando el bien jurídico su función protectora al intervenir el Derecho Penal cada vez con más frecuencia en el ámbito social.

Los autores consideran que la creación de bienes jurídicos colectivos debe determinarla la necesidad de proteger intereses personales relacionados con estos ante comportamientos que pueden ser potencialmente lesivos para un gran número de personas, debe fundamentarse en la importancia de los bienes jurídicos, debieran configurarse tipos penales de los bienes jurídicos colectivos que sean de peligro concreto o de un peligro abstracto concreto donde se exija una conducta capaz de poner en peligro el bien jurídico individual, aunque se pueda prescindir de comprobar la puesta en peligro.

\section{Conclusiones}

Teniendo en cuenta el análisis desarrollado en esta investigación podemos concluir, primeramente, la anticipación de la tutela penal es aquel conjunto de técnicas y procedimientos de los que se vale el legislador para anticipar la intervención punitiva, es la principal característica del Derecho Penal de riesgo o de lo que es lo mismo, de la tendencia expansionista del derecho penal.

El desarrollo de las nuevas tecnologías y los avances en las ramas de las ciencias son causas determinantes del surgimiento de un nuevo derecho penal adaptado a las circunstancias actuales, pero en ocasiones en su intento de prevenir los riesgos de la sociedad moderna no utiliza los métodos más indicados pues estos inciden directamente en la libertad individual que puede verse limitada con la proliferación de normas penales que intervienen cada de forma más anticipada.

En Código Penal cubano están presentes varias técnicas de anticipación de la tutela penal como los delitos de peligro, los delitos de

Revista de Ciencias Sociales - Número 70 (2017) - Universidad de Valparáíso - ISSN 0716-7725-Valparáiso, Chile 
tentativa, los delitos de preparación o actos preparatorios, los delitos de intención sin lesión al bien jurídico y la creación de bienes jurídicos colectivos. Los delitos de peligro, generalmente de peligro abstracto que ha devenido principal técnica de anticipación penal, por los diversos motivos expuestos con anterioridad deberían aceptarse excepcionalmente en nuestro Código Penal.

Deben no sólo buscarse, sino encontrarse límites al poder punitivo, para mantener la eficacia y credibilidad del sistema penal, pues el uso indiscriminado del poder punitivo puede lesionar su efectividad, si se muestra insuficiente para hacer frente a una excesiva cantidad de violaciones se debilitará; entre menos haya que recurrir a una norma penal más eficiente será esta pues demostrará que solo una minoría social incurre en ese comportamiento delictivo, pero antes de acudir a ella deben probarse otros mecanismos de solución como pueden ser la acción civil y las sanciones no penales como las administrativas.

Debe respetarse el principio de intervención mínima o de ultima ratio que es contrario al expansionismo penal y acudir al Derecho Penal cuando las otras ramas del ordenamiento jurídico han sido ineficaces, ante los ataques más graves a los bienes jurídicos más importantes, por lo que pese a las peligrosas situaciones que puedan presentarse en la "sociedad de riesgo" no puede por ello el Derecho Penal en la actualidad dejar de estar en consonancia con sus principios.

\section{BIBLIOGRAFÍA}

ROXIN, Claus: tI, Fundamentos, La estructura de la teoría del delito (traducción a la 2 da edición alemana y nota por D. M. Luzón Peña, M. Díaz y García Conlledo, y J. De Vicente Remesal), reimp., 2006, Ed. Civitas, Madrid, p. 62.

BUSTOS RAMÍREZ, J. J., y H. HORMANAZÁBAL, Malarreé (1999) Lecciones de Derecho Penal, vol. II, Ed. Trotta, S. A., Madrid.

MUÑOZ CONDE, F., y GARCÍA ARÁN, María (2004): Derecho Penal, Parte General, 6ta ed., revisada y puesta al día, Ed. Tirant

Lo Blanch, Valencia.

SÁNCHEZ GARCÍA DE PAZ, M. I. (1999) El moderno Derecho Penal y la anticipación de la tutela penal, Secretario de Publicaciones e Intercambio Científico, Universidad de Valladolid, Valladolid.

Facultad de Derecho y Ciencias Sociales - Universidad de Valparaíso - Chile 
LÓPEZ CELEIRO, Idalmis. Los delitos de peligro: ¿Desafío o necesidad para el Derecho Penal contemporáneo? (2010) Boletín ONBC, $\mathrm{N}^{\circ}$ 42, Ediciones ONBC, La Habana, pp. 25-38.

SOLÓRZANO SOLÓRZANO, A. G.; QUIJANO LÓPEZ, H. R. y L.

E. Cortez Figueroa (2004): Principio de lesividad, tesis en opción de Licenciado en Ciencias Jurídicas, Facultad de Jurisprudencia y Ciencias Sociales, Universidad Francisco Gavidia, San Salvador.

MEDINA CUENCA, Arnel (2001): Los principios limitativos del ius puniendi. Su incidencia en la determinación de la pena y su consagración en las constituciones nacionales y en los instrumentos jurídicos adoptados por la comunidad internacional. Trabajo de investigación defendido en opción del título de Máster en Derecho público, en el Departamento de Derecho Penal de la Facultad de Derecho de la Universidad de Valencia, España.

QUIROS PÍREZ, Renén (1999): "Manual de Derecho Penal. Tomo I. Editorial Félix Varela, La Habana.

ZAFFARONI, Eugenio Raúl (1998) Tratado de Derecho Penal. Parte General. Tomo I. EDIAR. Buenos Aires, Argentina. 